\title{
TRANSFORMACIONES TERRITORIALES RECIENTES EN EL LITORAL SUR DE LA RMB \\ Un Camino de Gestión Posible
}

\section{Juan Carlos Etulain}

Arquitecto, (Facultad de Arquitectura y Urbanismo de la Universidad Nacional de La Plata -FAU, UNLP-), especialista en Ciencias del Territorio (FAU, UNLP), doctorando en Arquitectura (Facultad de Arquitectura, Diseño y Urbanismo de la Universidad de Buenos Aires -FADU, UBA-). Es profesor de la Cátedra de Metodología de Investigación en la Escuela de Turismo de la Universidad Nacional de La Plata, docente del Taller Vertical de Arquitectura 3 Sessa/Fisch/Prieto en la FAU y del Taller de Planeamiento Físico 1 Bono/ Laurelli/López, UNLP. Es investigador de la Unidad 5 del Instituto de Estudios del Hábitat desde 1992, ha sido becario de Iniciación, Perfeccionamiento y Formación Superior de la UNLP y becario posdoctoral de Conicet, actualmente es prosecretario de Investigación de la FAU, UNLP. Ha asistido como ponente en diversos eventos nacionales e internacionales relacionados con el crecimiento y la forma urbana de las ciudades intermedias y centrales. Los trabajos y artículos referidos a su línea de investigación han sido divulgados en diversas revistas, publicaciones y eventos internacionales. 


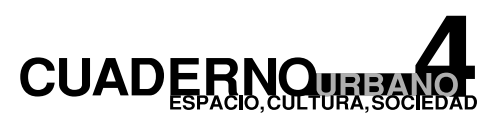

12

\author{
Transformaciones Territoriales Recientes en el Litoral Sur de la RMBA \\ Un Camino de Gestión Posible
}

\begin{abstract}
Resumen:
El artículo tiene como propósito focalizar, desde los puntos de vista analítico, empírico y propositivo las transformaciones producidas en los 90 en un área particularmente sensible de la Región Metropolitana de Buenos Aires (en delante RMBA): el Litoral Sur, a partir del anuncio (Puente Punta Lara - Colonia) y la ejecución (Autopista La Plata - Buenos Aires) de importantes emprendimientos que mejorarían su accesibilidad y por lo tanto sus oportunidades de transformación. En este marco, se delimita y caracteriza el área de análisis, se identifican las transformaciones territoriales producidas remarcando los principales problemas emergentes, y se formulan posibles caminos para enfrentarlos pensando en una transformación con oportunidades más equitativas para la población actual y futura.
\end{abstract}

\begin{abstract}
:
This article has the purpose of focusing - from the analytical point of view as well as from the empiric one- and establishing a possible management way in relation to the transformations occurred in the 90's in a particularly sensitive area of the Metropolitan Region of Buenos Aires (referred to as RMBA) and the Southern Coast since the announcement (Punta Lara - Colonia Bridge) and construction (La Plata - Buenos Aires Highway) of relevant undertakings that (would) improve its accessibility and thus its transformation opportunities. Within this frame the analysis area is defined and characterized, the territorial transformations produced are identified stressing the main emergent problems and the possible ways to face them are formulated considering a transformation with fairer opportunities for the present and future population.
\end{abstract}




\section{Juan Carlos Etulain}

Transformaciones Territoriales Recientes en el Litoral Sur de la RMBA Un Camino de Gestión Posible

\section{DELIMITACIÓN Y CARACTERIZACIÓN DEL LITORAL SUR}

El espacio litoral — según Barragán Muñoz (1994), al menos en lengua castellana— no ha sido capaz de generar igual que otras unidades físico-territoriales, un glosario relativamente delimitado y definido. La distinción entre términos aparece casi siempre ligada a la función que cada disciplina o ciencia le haya otorgado. No obstante, se constata un factor común que lo configura en un hecho real e indiscutible, "la existencia de una zona de anchura variable, que aparece como resultado del contacto dinámico entre la hidrosfera y la litosfera". Por lo tanto, el carácter dinámico del medio acuático, en este caso el Río de La Plata, en contraste con la mayor estabilidad del espacio terrestre, anula parte de las ventajas derivadas de que simplemente la delimitación sea sólo una línea, con lo cual el contacto resultante pasa a convertirse en una franja o banda variable. Por lo tanto, la fijación de límites precisos de un espacio litoral que sea válida, es propia de cada territorio y constituye una dificultad del tipo de fenómeno descripto.

En este marco, en el Área Litoral Metropolitana, comprendida entre el delta y la desembocadura del río, debería definirse el ancho de la franja a partir de las variables que respondan a su rol y a su función, y en respuesta a la problemáticas que se planteen. El Litoral Sur Metropolitano formaría parte de esta franja, entre el riachuelo y la desembocadura. (Ver Figura l)

De esta forma, el análisis debe recortarse fundamentalmente, a partir de su caracterización como parte integrante de una región natural, y con el marco jurídico y jurisdiccional aplicable a la ribera del Río de La Plata. Su delimitación, por lo tanto, debe definirse a partir de variables como: su dinámica natural, lo normativo y lo jurisdiccional.

Desde su naturaleza y/o como perteneciente a una región natural, porque debemos tener en cuenta que el río no reconoce los límites impuestos por el hombre. Periódicamente, reclama sus áreas de expansión a partir de inundaciones cíclicas. Además el río, es fuente de agua dul- 


\section{CUADERNA}

14

Transformaciones Territoriales Recientes en el Litoral Sur de la RMBA

Un Camino de Gestión Posible

1-Para su análisis se la considera conformada por la Ciudad Autónoma de Buenos Aires (200 Km2 y 2.955 .002

hab.) y conurbano (40 partidos, con $13.777 \mathrm{~km} 2$ y 9.366 .280

hab.). Alinterior de este último, en función de la integración paulatina al Área

Metropolitana Tradicional (19 partidos, más sus divisiones y la Ciudad Central), se distingue: Gran Buenos Aires (24 partidos, con 3.680 Km2 y 7.969.324 hab., el Área Metropolitana Tradicional, sin la Ciudad Central), Gran La Plata (3 partidos, con $1.162 \mathrm{Km} 2 \mathrm{y}$ 664.903 hab.) y periferia (13 partidos, 8.935 Km2 732.053 hab., de reciente integración).

ce, vía navegable y regulador ambiental. Por su paisaje y riqueza biológica es un recurso esencial para la salud, la recreación y el esparcimiento; y su ribera constituye un patrimonio de espacio público común a todos los habitantes, siendo de este modo, un valioso elemento de nivelación social. (Ver Figura 2)

La ribera se extiende sobre una planicie con escasa capacidad de evacuación natural de las aguas; está dominada en casi toda su extensión por una terraza baja. A partir de que el Río de La Plata tiene régimen estuárico, las mareas suben, lo embalsan e impiden volcar sus aguas al mar. Las frecuentes sudestadas actúan como tapón de todos los arroyos efluentes. Por lo tanto, las inundaciones periódicas y cíclicas mencionadas han llegado a cubrir toda la terraza baja. Esto determina que el área de ribera sea una zona de riesgo hídrico, que se comprueba cuando se registran abundantes precipitaciones en presencia de sudestada.

Desde lo jurisdiccional, es un espacio complejo, en principio por ser parte de una Región Metropolitana ${ }^{1}$ donde no existe autoridad única reconocida, ni antecedentes que vislumbren su posible formación. Históricamente, estuvo conformada por una ciudad central, un territorio nacional, que desde 1996 se constituye en la Ciudad Autónoma de Buenos Aires, y diecinueve partidos de la provincia de Buenos Aires que se rigen por la Ley Orgánica de las Municipalidades y no son autónomos. Además, en materia de ordenamiento de transporte e infraestructura, están bajo el régimen provincial, nacional y/o empresas privatizadas, según de que se trate.

La ribera es jurisdicción de la provincia de Buenos Aires, aunque generalmente la administran los municipios. Por otro lado, si bien existe una ley de ordenamiento territorial (ley 8912), en la que uno de los objetivos centrales es articular políticas en la Región Metropolitana entre la provincia y los municipios, aún no se han elaborado planes que establezcan lineamientos y reconozcan el litoral como un área desde su problemática y su potencialidad.

Desde el Código Civil, la ribera se reconoce como"aquella línea de demarcación geográfica del punto hasta donde se extiende el dominio publico". Se distingue una línea de ribera interna y otra 


\section{Juan Carlos Etulain}

Transformaciones Territoriales Recientes en el Litoral Sur de la RMBA

Un Camino de Gestión Posible

Figura 1: Litoral Sur de la Región Metropolitana de Buenos Aires

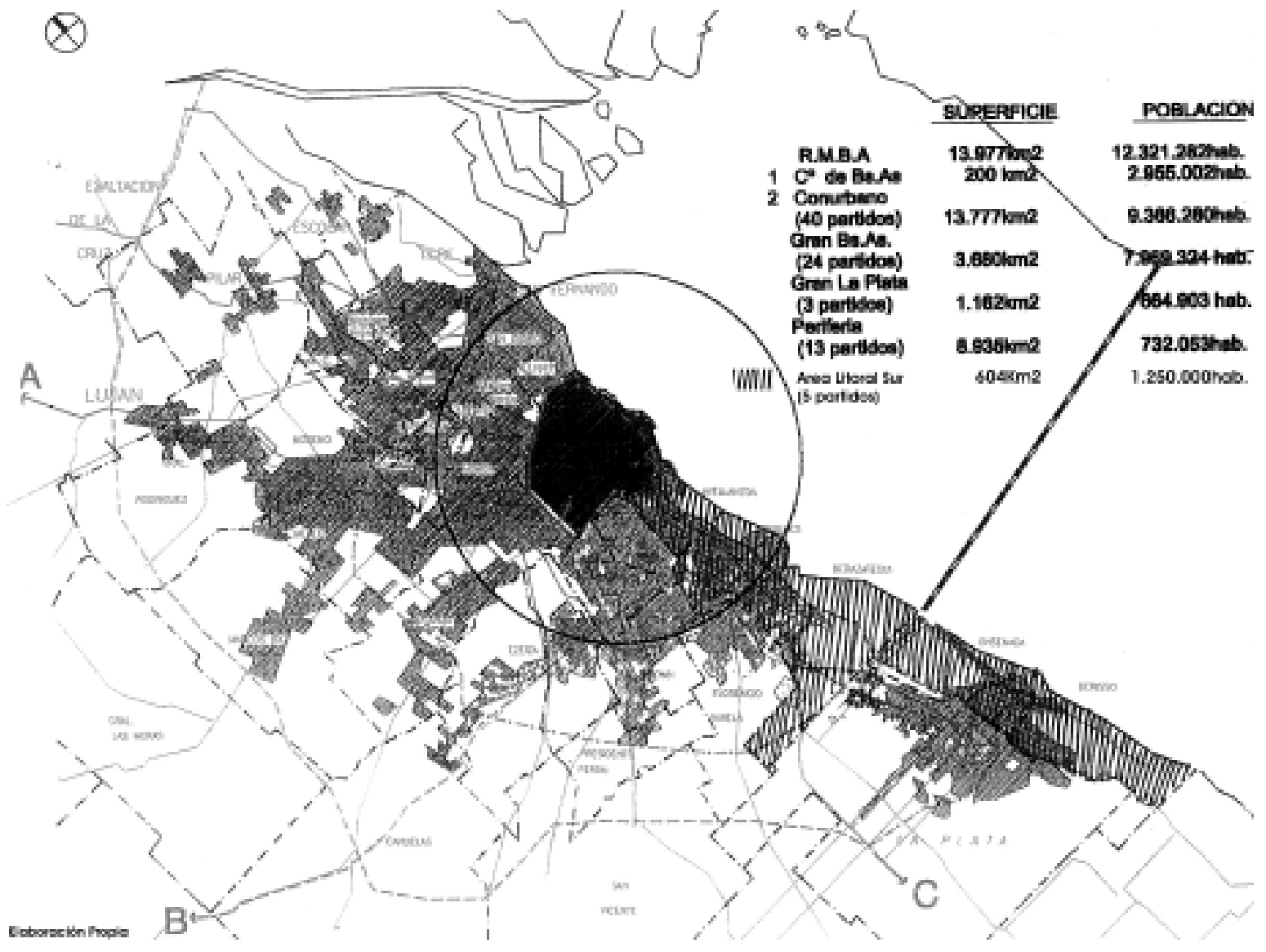




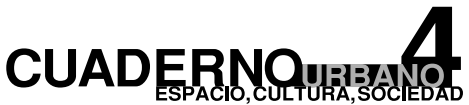

16

Transformaciones Territoriales Recientes en el Litoral Sur de la RMBA

Un Camino de Gestión Posible

Figura 2: Medio Natural

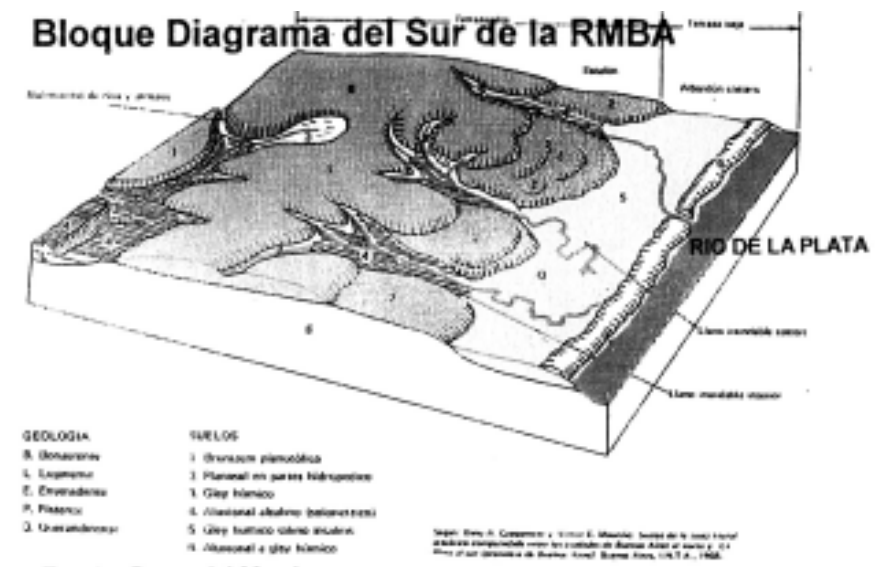

Fuente: Cappanini-Maurino.

En Chiczza, E.; El Pais de los Argentinos,

Buencs Aires. CEAL, 1996

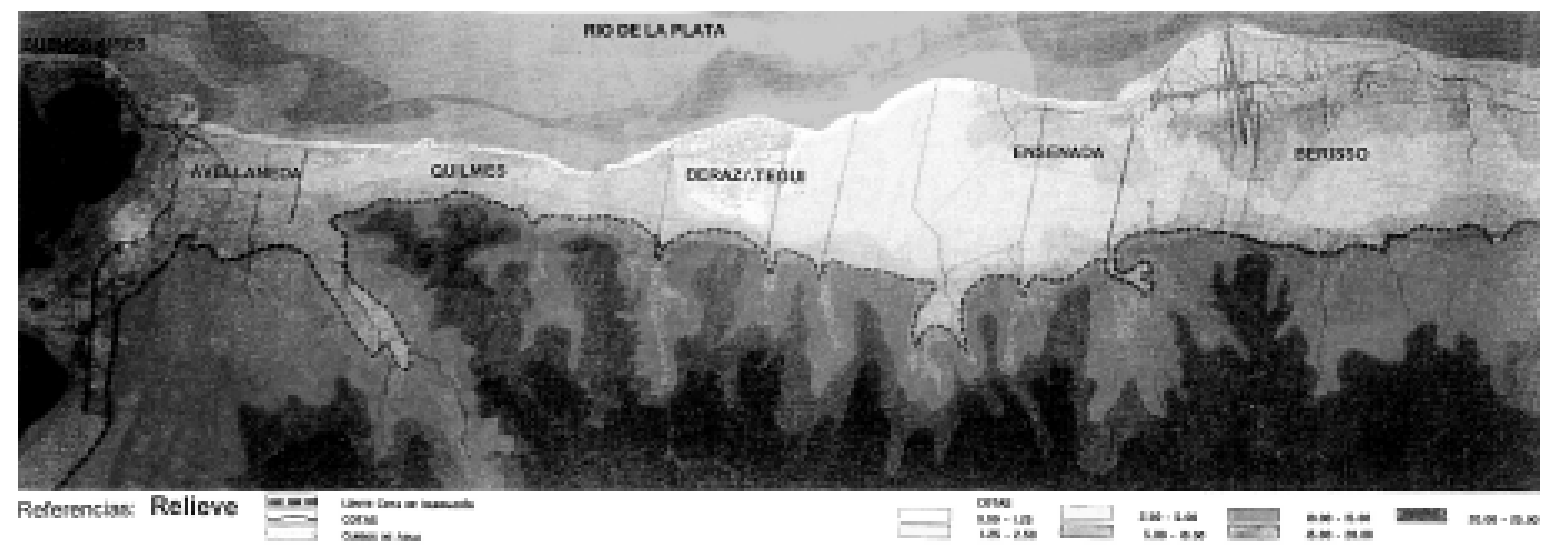

Elaboración: Bono-López-Roca-Seimandi-Etulain 


\section{Juan Carlos Etulain}

Transformaciones Territoriales Recientes en el Litoral Sur de la RMBA Un Camino de Gestión Posible

externa, la primera es siempre del dominio público estatal y los propietarios privados que tengan propiedades sobre esa línea están obligados a dejar una calle o camino público de 35 metros hasta la orilla. La línea interna puede ser de dominio público o privado.

Sin embargo, hay una ausencia de regulación o legislación específica en materia de delimitación de cada litoral, así como de protección, conservación y recuperación de áreas costeras y ribereñas, tanto a nivel nacional como provincial. La ley provincial 8912, al referirse a la planificación y el ordenamiento no hace alusión a la zona costera o ribereña: solamente reconoce en el artículo 52 las áreas urbanas frente al Litoral del Río de La Plata y el océano Atlántico (hasta $5 \mathrm{Km}$. desde la ribera) ordenando sólo las medidas de la subdivisión de la tierra. El artículo 59 reconoce que al crear o ampliar núcleos urbanos que estén sobre cursos de agua, se deberá ceder al fisco de la provincia un ancho de 50 metros a contar desde la línea de máxima creciente, que será determinada por la Dirección Provincial de Hidráulica. Hasta el momento para este caso, no efectivizada. Además, en el Río de La Plata se superponen competencias con otros organismos.

También, a partir de los efectos causados por las inundaciones que soportó el litoral en 1940 y 1957, y que se repitieron cíclicamente llegando a veces hasta la terraza alta, en 1960 se sancionaron las leyes 6253 y 6254 que reglamentan al respecto, sin embargo son contradictorias. La primera crea las zonas de conservación de desagües naturales, con anchos mínimos de 50 metros, luego plasmado en el artículo 59 de la ley 8912, y aunque prohíbe en la zona de conservación variar el uso, la misma ley lo exceptúa, cuando los planes reguladores de cada municipio establezcan la necesidad imperiosa de levantar la restricción, haciendo las obras necesarias para asegurar condiciones de seguridad y sanidad.

Por otro lado, la ley 6254, a pesar de que prohíbe los loteos en todas las áreas de cota inferior a 3,75 IGM, exceptúa de esa prohibición a las tierras donde se realicen obras de saneamiento integral público y/o privado, y a las tierras comprendidas en los municipios que cuenten con planes reguladores. Además, establece - frente a las playas del Río de La Plata y desde la línea de ribera hasta los mil metros de profundidad- la posibilidad de frac- 


\section{CUADERMQR}

18

Transformaciones Territoriales Recientes en el Litoral Sur de la RMBA

Un Camino de Gestión Posible

2-Con 7,4 Km. en Avellaneda, 9 Berazategui, $12 \mathrm{Km}$. en Ensenada y 22 Km. en Berisso. cionar el territorio para vivienda transitoria y cotas de terrenos superiores a 3,75 m.snm., al igual que los pisos de los locales habitables que no deberán ser inferiores a 4 m.snm. (Situación que debieran exigir las ordenanzas municipales, pero que en realidad no se implementan).

En este marco, el litoral del Río de La Plata se define como parte de una región natural que en el espacio terrestre tiene cotas que van de los 1,25 hasta los 5 metros, aproximadamente, del nivel del mar. Por lo tanto, a partir de los procesos cíclicos de inundación de esta planicie, de su composición geológica y del reconocimiento de esa circunstancia que hacen las propias leyes (como cota de nivel de piso mínimo de $4 \mathrm{~m} . \mathrm{snm}$.), se puede concluir que este espacio que va desde el Riachuelo hasta la culminación del Bañado Maldonado, es por definición desde la dinámica natural el espacio Litoral Sur del Río de La Plata, aunque existan contradicciones y lagunas en lo normativo.

El Litoral Sur tiene una ribera de 70 kilómetros ${ }^{2}$ sobre el Río de La Plata de un total de 110 Km. de la RMBA (30 Km. Litoral Norte y $10 \mathrm{Km}$. Ciudad de Buenos Aires). Está integrado por los partidos de Avellaneda, Quilmes, Berazategui, Ensenada y Berisso; cuenta con una población de aproximadamente 1.250.000 habitantes y una superficie de 604 kilómetros cuadrados, de los cuales 392 (el 65\%) pertenecen a la terraza baja del Río de La Plata. Prácticamente, coincide con la línea del Ferrocarril General Roca, entre el riachuelo y el bañado Maldonado, correspondiente a parte de los partidos de Avellaneda (90\%), Quilmes (25\%), Berazategui (30\%) y el total de las jurisdicciones de Berisso y Ensenada. (Ver Figura 1)

Se puede decir en forma general y desde lo físico-espacial, que está ocupado por actividades productivas, áreas residenciales y recreativo-turísticas en forma totalmente fragmentaria y con predominio de los espacios abiertos. De aquí, la necesidad de reconocer en él un espacio problemático en transformación, caracterizado por conservar aún grandes espacios abiertos con tendencia a una apropiación social de tipo privado y selectivo. Por lo tanto, a los fines de dimensionar el compromiso del área, su tendencia y posibilidades de 


\section{Juan Carlos Etulain}

Transformaciones Territoriales Recientes en el Litoral Sur de la RMBA Un Camino de Gestión Posible

reordenamiento, se considera importante su análisis y evaluación, con el fin de encontrar indicios posibles para la gestión de su ordenamiento.

\section{LAS PROBLEMÁTICAS ESTRUCTURALES}

En el Sur de la RMBA, como en otros territorios, se verifica la existencia de condiciones específicas que derivan de su situación histórica, social, espacial y ambiental, marcada en los últimos años por una creciente desindustrialización y terciarización de la economía, con su correlato en términos de desempleo y precarización laboral, marginalidad social y pobreza.

Está configurado por un proceso de urbanización-conurbación ligado al sistema de movilidad Buenos Aires-La Plata, junto a otros de grandes espacios abiertos constituido por areas vacantes, planicies de inundación del Río de La Plata y el Parque Público Pereyra Iraola. Esta circunstancia a su vez, otorga una excepcional potencialidad de reordenamiento ligada a los mismos elementos: un sistema de movimientos que permite satisfacer la alta demanda de movilidad existente en el área y una gran disponibilidad de espacios abiertos en forma continua, con presencia de selvas marginales o en galería en estado natural en Hudson y Punta Lara y una importante vegetación en el monte costero de Ensenada y Berisso. Un auténtico parque ecológico metropolitano polifuncional, en grado de constituir una excepcional reserva ecológica en función de un nuevo equilibrio territorial planificado. Este sistema litoral-parque constituye una reserva de espacios abiertos continua de aproximadamente 30.000 has, que representan para la población asentada una dotación teórica de $240 \mathrm{~m} 2 /$ hab., inconfrontable con la dotación media de que disponen las grandes concentraciones metropolitanas del mundo, mucho menos con las del Cono Sur.

Desde lo fitogeográfico, el litoral es parte de la Región Neotropical. Los tipos de vegetación de la terraza baja son selvas marginales, monte natural y comunidades palustres (pajonales, totorales y juncales) y los dos únicos fragmentos de selva protegidos están en el Litoral Sur 


\section{CUADERNQ}

Transformaciones Territoriales Recientes en el Litoral Sur de La RMBA

Un Camino de Gestión Posible

3- Aptitud del suelo (en un rango de aptitud favorable que va desde la Clase I a VIII) que varía entre Clase VIw a VIII (Miaczynski 1961)

4- Otras crecidas importantes han sido las del 27-28 de julio de 1958, con un pico de $+3,85 \mathrm{mtrs}$; el $12 \mathrm{de}$ noviembre de $1989 \mathrm{de}+4,06 \mathrm{mtrs} ; \mathrm{y}$ la del 7 de febrero de 1993 de $+3,94$ mtrs. sobre el cero del semáforodel riachuelo. (Nussbaum 1997) en Hudson (Pdo. de Berazategui) y Punta Lara (Pdo. de Ensenada). Además, aún conserva su estructura natural no modificada totalmente, situación que le da un gran valor ecológico.

Desde su geomorfología está constituido, como ya se mencionó, por una planicie de un ancho variable de aproximadamente 1,5 a $10 \mathrm{Km}$. y que forma parte de la baja terraza o planicie costera. Comprende el llano inundable costero y el albardón (+1,5 m.snm) con una cota variable de 1,5 a $5 \mathrm{~m} . \mathrm{snm}$, que contrasta con los 10 a $30 \mathrm{~m} . \mathrm{snm}$. De los pertenecientes a la terraza alta o zona interior, que incluye el escalón (+5 a $10 \mathrm{~m} . \mathrm{snm}$ ) y las nacientes de los ríos y arroyos que de forma perpendicular desembocan en el Río de La Plata (Cappannini et al 1966). (Ver Figura 2)

Los suelos involucrados corresponden a la llanura pospampeana. Estos suelos presentan importantes limitaciones ${ }^{3}$ para su uso, la producción agrícola y el pastoreo. Por lo tanto, en espacios muy importantes la superficie se restringe a su aprovechamiento sólo para la recreación, conservación de la fauna silvestre y/o la provisión de agua con fines estéticos o deportivos. Sin embrago, estos suelos son importantes como espacio de protección de la cuenca del Río de La Plata.

También, la reiteración del fenómeno natural "sudestada" que provoca inundaciones, determina que el Litoral Sur sea una zona de riesgo hídrico. Siempre se inundan los mismos lugares: el llano inundable costero ( $-5 \mathrm{~m} . \mathrm{snm})$ y el llano inundable interior constituido por las cuencas de los ríos y arroyos. A modo de ejemplo y para comprender la magnitud del fenómeno, cabe señalar que en el período 1905-1994 se produjeron en 76 oportunidades crecidas extraordinarias, alcanzando su pico máximo el 15 de abril de 1940 cuyo registro fue una altura de $+4,44$ mtrs. sobre el cero del semáforo del riachuelo, lo cual provocó la inundación del área deltáica y de la ribera del Plata desde San Pedro hasta Magdalena. Se anegaron 465.000 hectáreas $(4.650 \mathrm{Km} 2)^{4}$. 


\section{Juan Carlos Etulain}

Transformaciones Territoriales Recientes en el Litoral Sur de la RMBA Un Camino de Gestión Posible

El asentamiento humano que está expuesto al riesgo de inundación y es objeto de gran vulnerabilidad, se ha construido históricamente a partir de dos posturas bien diferenciadas: una que asume el compromiso de un determinado tipo de desarrollo - ambientalmente sustentable - y otra que se produce a partir de un desconocimiento total de la relación posible con el río; y que surgen como consecuencia del asentamiento de población excluida de otros sectores en procura de un hábitat accesible económicamente. Esto determina desde un comienzo la incomprensión del medio en que se asientan.

Esta última postura, hace que el asentamiento presente un desarrollo inapropiado con el medio, al incorporar un patrón tipológico convencional que se asienta a nivel del terreno y desconoce las inundaciones cíclicas frecuentes en el área y/o se impone al mismo con operaciones de relleno. Mientras que la otra postura, interpretada como un desarrollo apropiado al medio, utiliza un patrón tipológico sustentable y posible, como es la construcción palafítica.

Como resultado, vastos sectores de población del Litoral Sur deben ser evacuados de sus hogares con cierta frecuencia. La asociación de sudestada y desborde de río y arroyos induce a la generación de un conflicto social de extrema gravedad. Por otro lado, los asentamientos humanos intensivos presentes en la terraza baja se pueden clasificar a su vez en: (Ver Figura 3)

* El sub-sistema de quintas Sarandí y monte costero e islas de Ensenada y Berisso, que constituyen un claro ejemplo de espacio, socialmente caracterizado y productivamente integrado. La ocupación del espacio se produce a partir de un patrón tipológico alternativo: vivienda palafítica que genera una apropiación correcta con la dinámica del medio natural. De esta manera, se percibe una distendida espera de las crecidas del río, con el que conviven desde su aparición.

* El sub-sistema de recreos y balnearios de Quilmes y Punta Lara. 


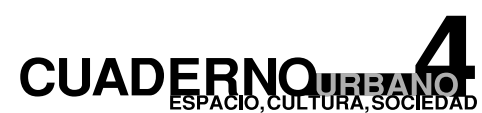

Transformaciones Territoriales Recientes en el Litoral Sur de la RMBA

Un Camino de Gestión Posible

* El sub-sistema de urbanizaciones en torno a las actividades recreativas y los núcleos urbanos principales de los partidos de Ensenada y Berisso constituyen asentamientos en los que prevalece el patrón de asentamiento convencional sobre el terreno natural, con edificación que en épocas de crecida el agua alcanza en su interior 1.10 metros de altura aproximadamente. Aquí, aunque predomina el desarrollo de tipologías inapropiadas con el medio, también existen intervenciones aisladas con tipologías apropiadas (viviendas palafíticas). Lo paradójico de la situación es que ambos patrones se dan en relación de contigüidad, aunque cuantitativamente predomina lo inadecuado.

* Y por último, las villas y asentamientos precarios actualmente en crecimiento, localizadas en los bordes de arroyos y zonas muy degradadas o marginales del tejido tradicional, asentados sobre el terreno natural, por lo cual se ven castigados por las inundaciones frecuentes que se producen en el área.

Otro aspecto característico común a otros espacios litorales es la concentración de plantas de tratamiento de efluentes urbanos e infraestructuras de transporte. Los puertos de Buenos Aires y La Plata; los polos petroquímicos de Dock Sud y Ensenada, la autopista La Plata-Buenos Aires, la línea del Ferrocarril Roca (desde 1993 Ferrocarriles Metropolitanos), las plantas potabilizadoras de agua de Bernal y Punta Lara; la localización de la descarga cloacal; la penetración de la red de alta tensión de Edesur paralela al arroyo Plátanos; y la localización de la planta receptora del sistema radioeléctrico de la Policía Federal constituyen entre otros, ejemplos de esta concentración.

Como característica común, puede afirmarse que algunas funciones que se desarrollan interfieren con el normal desenvolvimiento de otras. El ejemplo más notorio es que la inexistencia de depuradores de algunos efluentes vertidos al río provoca su contaminación, obligando a alejar en sucesivas ocasiones las tomas de agua de las plantas potabilizadoras (en Bernal y Punta Lara). Al impacto directo le suceden los indirectos; el uso del río como bal- 


\section{Juan Carlos Etulain}

Transformaciones Territoriales Recientes en el Litoral Sur de LA RMBA

Un Camino de Gestión Posible

Figura 3: Caracterización y condiciones de ocupación

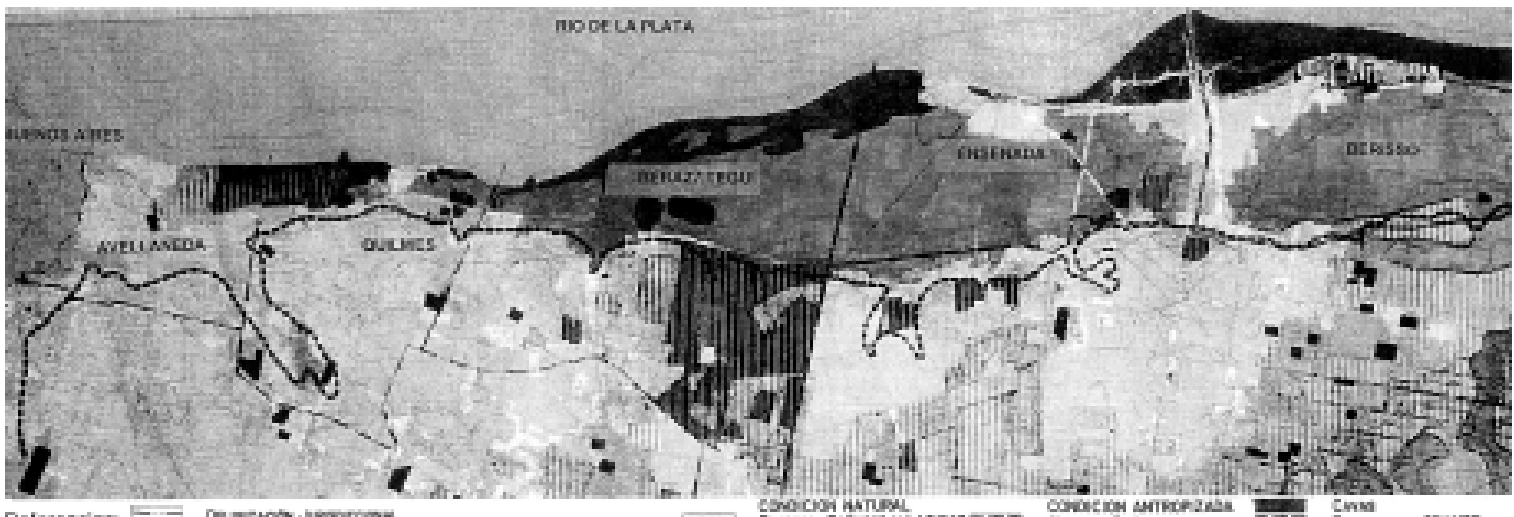

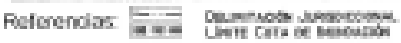

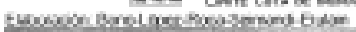
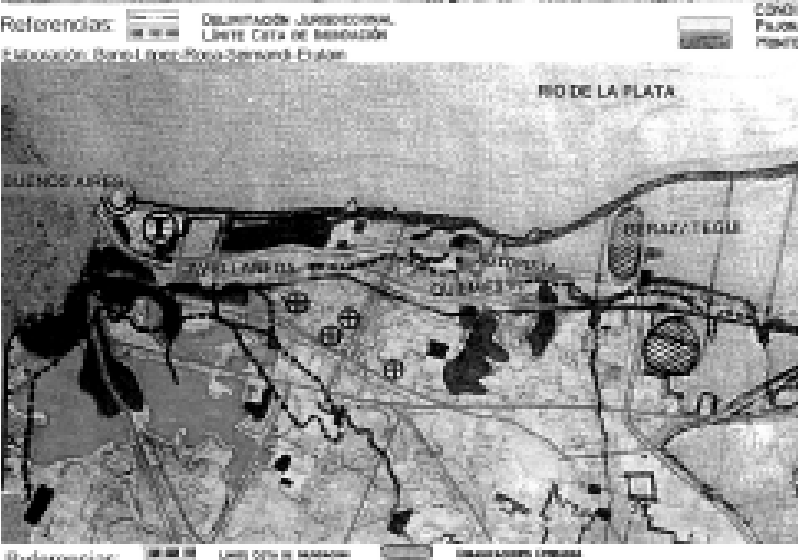

chas

Chume on cever

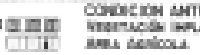

motecunata

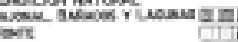




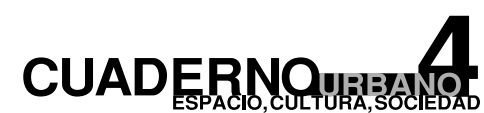

Transformaciones Territoriales Recientes en el Litoral Sur de la RMBA

Un Camino de Gestión Posible

neario se ve impedido o al menos disminuido (los de Quilmes, Punta Lara y Berisso), lo que implica un recorte sustancial del papel que el espacio ribereño debe jugar en relación con la recreación de la población, incluso se entiende que es el preludio de un desinterés generalizado del ciudadano medio y de la administración pública, que posteriormente justificará su privatización por el estado de abandono.

Entre los espacios abiertos predominantes en el Área Litoral —además del mencionado Parque Pereyra Iraola - existe un mínimo de tierras de uso productivo rural intensivo (álamos y sauces), ganadería extensiva en la terraza baja e inundable de Berazategui y sectores frutihortícolas en las quintas de Sarandí (tierras degradadas por la actividad minera con cavas de 12,5 y hasta 100 has, algunas de ellas anegadas). En tierras bajas de magnitud importante entre Avellaneda y Quilmes y en Ensenada, se ubican los depósitos de basura más importante del Area Sur Metropolitana, tratadas como relleno sanitario a partir de la intervención del CEAMSE, que aparecen como un mosaico entre los fragmentos de bañados y vegetación natural, como en el caso de las 400 has. En Villa Dominico y el relleno en el bañado Maldonado de Ensenada. Finalizando la descripción, se puede mencionar los $41 \mathrm{sec}$ tores vacantes que ocupan 700 has, desde Quilmes a Punta Lara y un fragmento entero de 800 has. de pastizales.

Desde la ocupación físico-espacial es importante reconocer que hasta el comienzo de la ejecución de la autopista Buenos Aires-La Plata este espacio litoral fue utilizado prácticamente como lugar de asentamiento del transporte acuático en los puertos de Avellaneda y La Plata y actividades industriales articuladas a ellos, especialmente dedicadas a la transformación del petróleo, carnes y cueros; sectores de producción agraria intensiva de abastecimiento local y otros que funcionaban solamente como parte del sistema de esparcimiento y recreación en contacto con el río.

En síntesis, hoy el Litoral Sur Metropolitano constituye —en gran parte- un escenario crítico, como consecuencia de la expansión de actividades y población sobre un territorio con riesgos ambientales cíclicos y permanentes. 


\section{Juan Carlos Etulain}

Transformaciones Territoriales Recientes en el Litoral Sur de la RMBA Un Camino de Gestión Posible

\section{TRANSFORMACIONES Y PROBLEMAS EMERGENTES}

Frente a las problemáticas estructurales revisadas, en la década de los 90 el Litoral Sur se encontró inserto en el marco de las transformaciones sufridas por los centros metropolitanos que disputaban su integración al sistema internacional y la hegemonía regional para convertirse en verdaderas "ciudades mundiales", sufriendo importantes transformaciones que impactaron en su estructura territorial con fenómenos de crecimiento y consolidación distintos a las pautas que tradicionalmente guiaron el área. Estas transformaciones, se relacionan con:

* La generación de megaproyectos de infraestructura continental, como los corredores Bioceánicos Atlántico-Pacífico, que en el Litoral Sur inciden a partir de la posible construcción del Puente Punta Lara-Colonia (Ver Figura 4), que conformaría parte del Corredor Bioceánico Centro y el eje vial San Pablo-Buenos Aires-Valparaíso.

* El gasoducto Argentina-Montevideo, de reciente habilitación (marzo 2003), tendido a través del río y que del lado argentino ingresa a la altura de Punta Lara, localidad de Ensenada.

* El mejoramiento de las condiciones de movilidad, a partir de la construcción parcial del nuevo corredor vial representado por la autopista La Plata-Buenos Aires (restando ejecutar el tramo final La Plata-ruta provincial 1l) (Ver Figura 4). Obra que en su integralidad forma parte de la trama circulatoria radial, que conjuntamente con la anular, redefinen la estructura vial de la RMBA con el fin de optimizar la estructura micro y macro territorial, que la posible construcción del puente exigiría. Además, desde 1993 se vienen registrando cambios en el sistema ferroviario metropolitano producto de las privatizaciones, que incluye en el Litoral Sur, la modernización y electrificación prevista a mediano plazo de Ferrocarriles Metropolitanos, empresa concesionaria del FF. CC. Gral. Roca. 


\section{CUADERNA}

26

Transformaciones Territoriales Recientes en el Litoral Sur de La RMBA

Un Camino de Gestión Posible

El incremento de la accesibilidad actual y potencial vinculado a las grandes obras de infraestructura antes indicadas, aportó un considerable valor agregado a las áreas cercanas de éstas, especialmente a los espacios abiertos existentes en relación con la Autopista La PlataBuenos Ares, dada su oferta de grandes superficies demandadas para nuevas modalidades comerciales, residenciales, de esparcimiento, etc. En este sentido, los espacios libres pertenecientes al sistema Litoral Sur adquieren una posición estratégica entre la nueva accesibilidad dadas por la autopista y el sistema ribereño, propiciando en esta importante reserva metropolitana, nuevas formas de apropiación social que inciden en su dinámica.

Figura 4: Grandes obras de infraestructura

\section{Autopista La Plata - Buenos Aires}

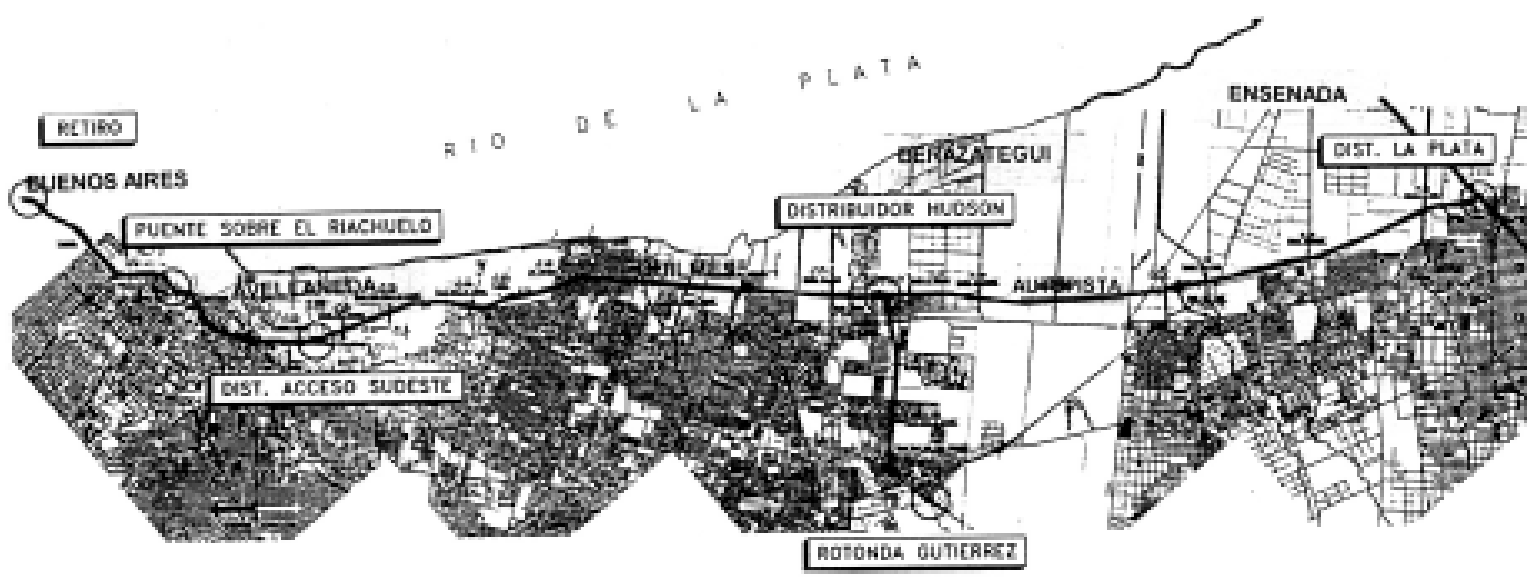

Fuente OCRABA 


\section{Juan Carlos Etulain}

Transformaciones Territoriales Recientes en el Litoral Sur de la RMBA

Un Camino de Gestión Posible

\section{Puente Punta Lara - Colonia}
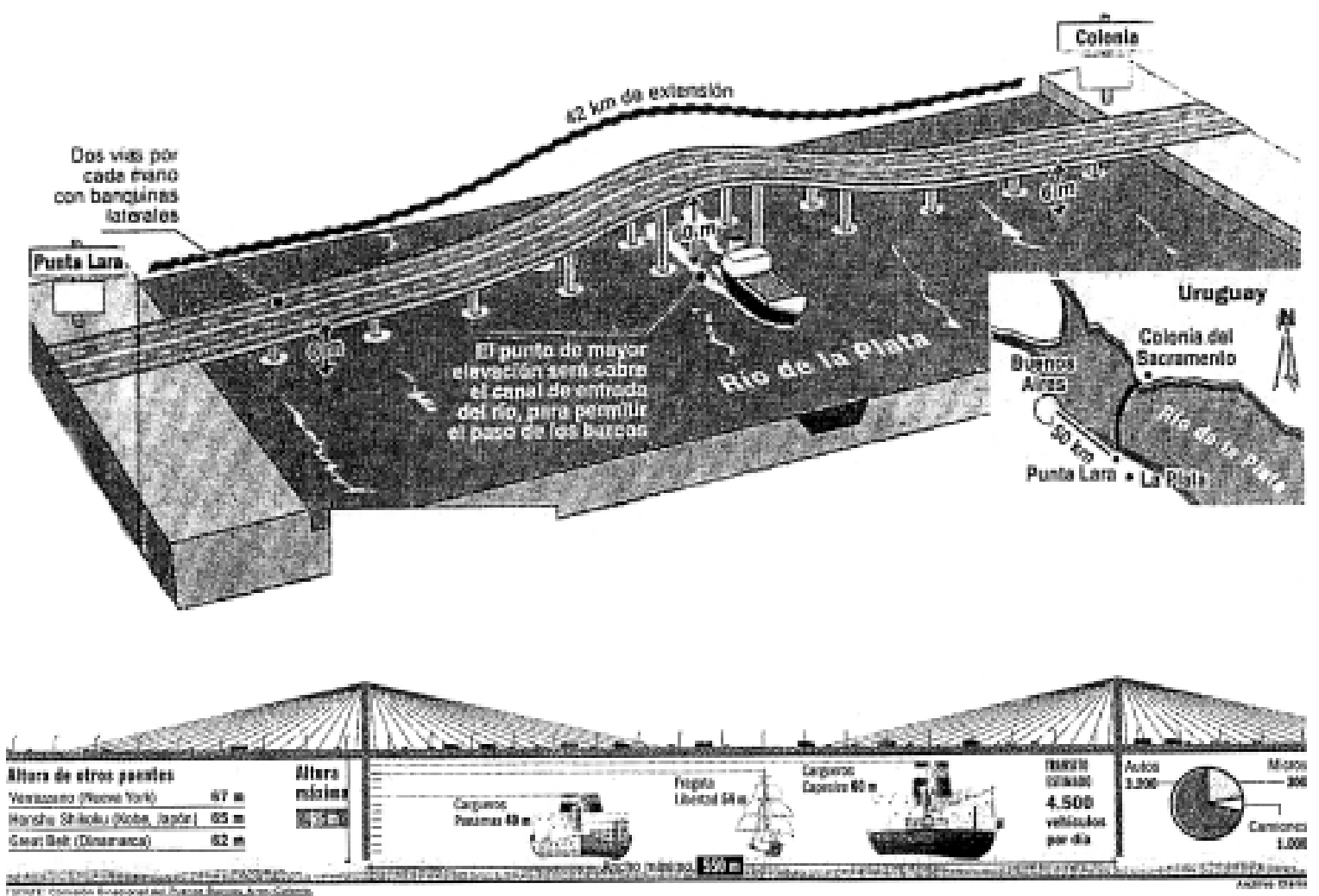

Fuente. Disrio Clärin 


\section{CUADERNQ}

Transformaciones Territoriales Recientes en el Litoral Sur de la RMBA Un Camino de Gestión Posible

* La infraestructura logística y de servicio para el transporte multimodal, a partir de la reconversión de los puertos de Buenos Aires, Dock Sud (privatizado) y La Plata. Se prevén proyectos de modernización y reactivación. Además, se suma la puesta en funcionamiento de la Zona Franca La Plata.

* Grandes equipamientos, como centros comerciales, de entretenimiento y espectáculos, que surgen a partir de nuevas empresas de comercialización muy concentradas, aprovechando el mejoramiento de las condiciones de accesibilidad mencionadas al localizarse en relación con las autopistas. En el Litoral Sur, se destacan el Parque Comercial Auchan, y Alto Avellaneda Shopping Mall, en Avellaneda; Easy Home, en Quilmes, sumado a las empresas hipermercadistas, como Carrefour, Wall Mart, Norte, Coto, Disco Ahold, Nini, etc., que se disputan el mercado existente. También se ubican en el área, los centros de distribución de estos grandes equipamientos comerciales.

* Urbanizaciones de gran escala, que al igual que en el caso anterior aprovechan el incremento de accesibilidad y dan lugar a un patrón de urbanización fragmentario y selectivo (en isla) que acentúa la segregación territorial y la constitución aggiornada de ghetos prefigurando un modelo de ciudad difusa y un uso extensivo e indiscriminado del territorio o del lecho del río, inclusive. Entre los principales emprendimientos privados se puede mencionar la macrourbanización de Codeco: la creación de un nuevo espacio ribereño por delante de la línea de ribera; y sobre el río, una isla con material refulado que va desde el arroyo Sarandí al norte hasta el inicio de la Selva Marginal de Punta Lara al sur. Otras iniciativas similares se prevén frente al borde costero de Punta Lara y sobre el bañado Maldonado en Ensenada; a los que se suman entre otros, las urbanizaciones ya construidas, Club de Campo Abril, Barrio Privado Victoria Village, Village del Parque, y la denominada Ciudad Náutica Puerto Trinidad en construcción sobre la terraza baja (actualmente paralizada), todos en Berazategui, los cuales, utilizan tipologías edilicias con pautas culturales pertenecientes a la terraza alta, incrementando las incompatibilidades con la dinámica propia del medio físico natural, revisadas. (Ver Figura 5) 


\section{Juan Carlos Etulain}

Transformaciones Territoriales Recientes en el Litoral Sur de la RMBA Un Camino de Gestión Posible

Estos nuevos asentamientos ejecutados o en ejecución sobre áreas originalmente inaccesibles y anegables dan como resultado el pasaje de condición de periferia aislada con asentamientos de usos degradados, a la de periferia integrada por su conectividad a la autopista y su vinculación actual o potencial con la línea de ribera. Por lo tanto, la tendencia marca que se abrió un nuevo frente de urbanización hasta hace poco no vislumbrado en un espacio, como se ha mencionado con una dinámica natural de riesgo ambiental.

* El incremento exponencial de villas y asentamientos precarios, que se distribuyen de manera diferencial en los partidos que la conforman. Un aspecto asociado a estos bolsones de pobreza en crecimiento, es la delincuencia y la violencia que en ellas se refugian, incidiendo en la inseguridad reinante que lleva a una progresiva desaparición de la vida barrial y con ella del uso y goce del espacio público.

* La planificación y gestión del territorio, que desde el Estado se adecua al modelo y el planeamiento va adquiriendo un carácter crecientemente facilitador, para dar respuestas a los intereses privados, a partir del uso discrecional en el ámbito municipal de la ley provincial de uso del suelo 8912 o la modificación de las normativas que regulan su uso y ocupación, para ofertar suelo posible de urbanizar en sectores ambientalmente comprometidos. (Ver Figura 6)

Se ha determinado (Bono et al 2000) que cada una de las jurisdicciones municipales ha contemplado en distinto grado y forma las mejoras en la accesibilidad interna y externa que sobre sus territorios genera la materialización de las grandes obras de infraestructura vial, así como las que aún se encuentran en estado de proyecto. En cuanto a las expectativas de inversión inmobiliaria, en la mayoría de los casos se manifiestan adecuaciones normativas que, de modo selectivo, mayoritariamente contemplan las nuevas modalidades de asentamientos residenciales cerrados, aún en áreas en que no se había registrado interés por parte de capitales inversores, entre las que se incluyen algunas localizaciones con alto riesgo ambiental, ya revisadas. 


\section{CUADERNA}

30

Transformaciones Territoriales Recientes en el Litoral Sur de la RMBA

Un Camino de Gestión Posible

A modo de ejemplo, se puede mencionar el cambio normativo realizado por el Partido de Berazategui, uno de los sectores del Litoral Sur más afectados por la presión inmobiliaria para la construcción de countries y barrios privados, donde en un sector calificado como Área Complementaria (AC), se aprobaron emprendimientos con características muy diferentes, recalificando una zona como Sector de Urbanización Especial (SUE), con una densidad de 450 hab./ha. para la ejecución del barrio privado Victoria Village y la fracción vecina se define como Zona Residencial 7 (R7), con una densidad de 150 hab./ha., para la realización del Club de Campo Abril.

Figura 5: Urbanizaciones de gran escala

\section{Proyecto de Defensa Costera y Urbanización del Conurbano Sur Bonaerense (CODECO)}

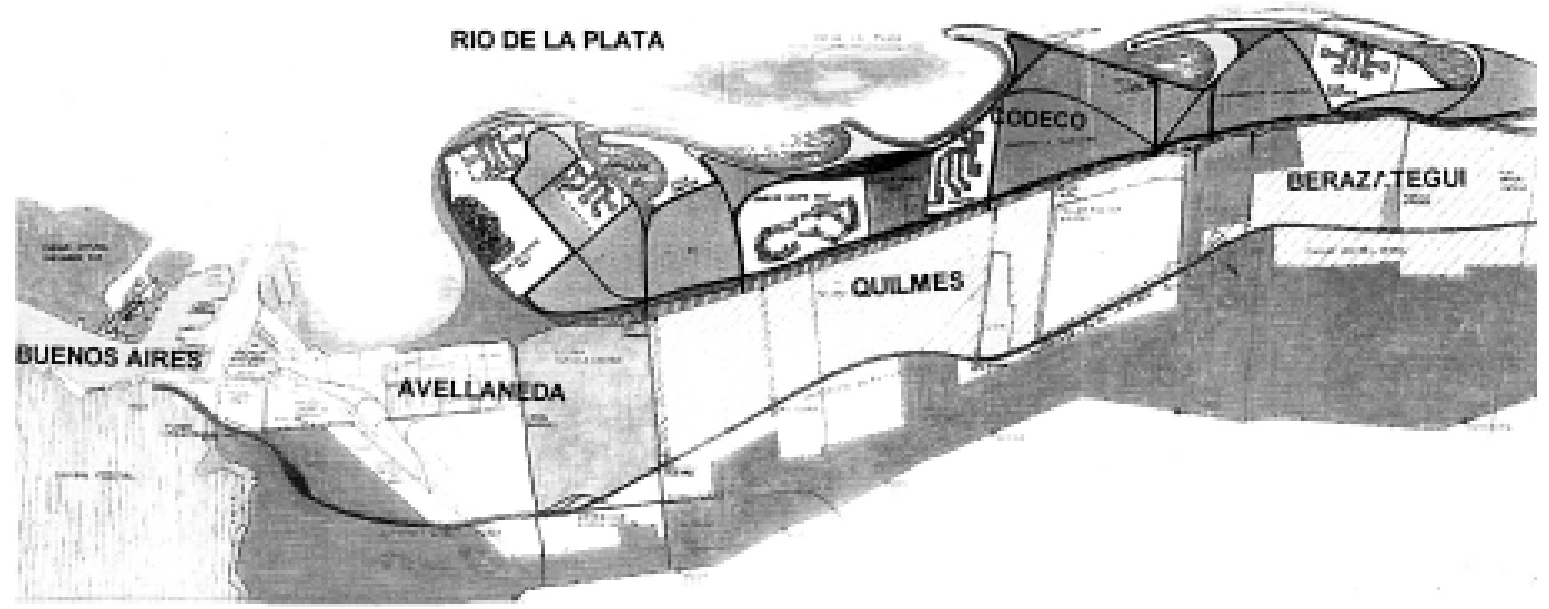

Fuenie: Empresa Promotora Hermasa 


\section{Juan Carlos Etulain}

Transformaciones Territoriales Recientes en el Litoral Sur de la RMBA

Un Camino de Gestión Posible

* La inexistencia histórica de una política que reconozca el litoral como un espacio con necesidades de ordenamiento y planificación, considerándolo como un sector de tratamiento especial por su fragilidad ambiental e importancia estratégica para la RMBA en su totalidad.

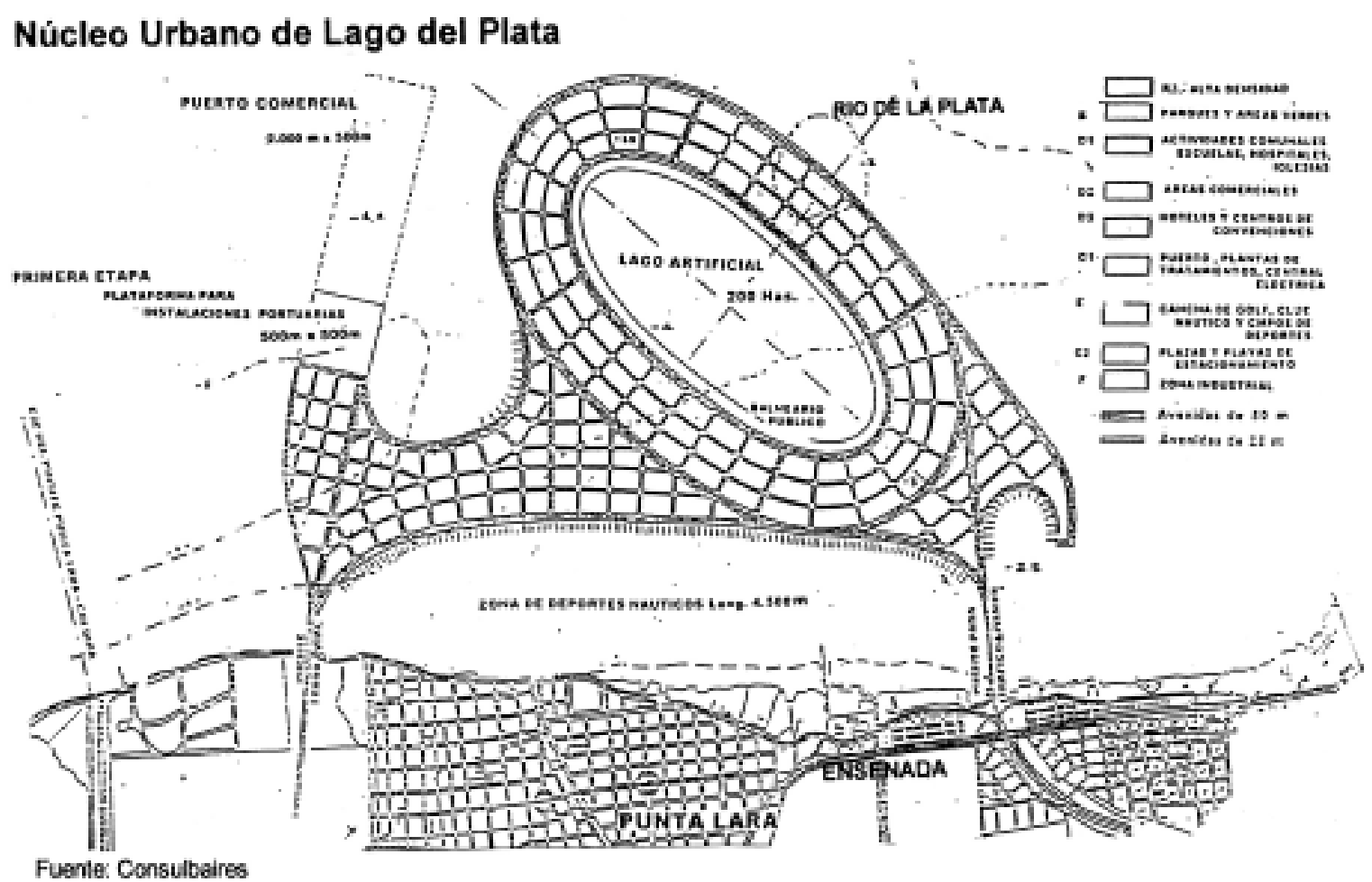




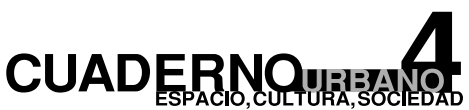

32

Transformaciones Territoriales Recientes en el Litoral Sur de la RMBA

Un Camino de Gestión Posible

En síntesis, cabe destacar dos hechos importantes que han impactado en éste espacio litoral, la progresiva pérdida del recurso a partir de la degradación ambiental del río y sus riberas y la marcada desaparición del carácter público de éste, sumado a la falta de información con relación a un diagnóstico integrado del Río de La Plata y el área litoral. (Ver Figura 7)

Por lo tanto, las principales transformaciones revisadas alertan sobre los efectos y los riesgos de los actuales procesos de metropolización y globalización. En este sentido, de continuar la tendencia actual de gestión del Litoral Sur, es factible prever el escenario tendencial posible en su desarrollo urbano-territorial, cristalizado mediante la acentuación del desarrollo urbanístico en isla o entre medianeras, siendo uno de sus principales factores determinantes, la exacerbada traslación al campo urbanístico de la hegemonía del mercado, proveniente del modelo de desarrollo vigente. (Ver Figura 8)

Figura 5: Urbanizaciones de gran escala

\section{Ciudad Náutica. Puerto Trinidad}
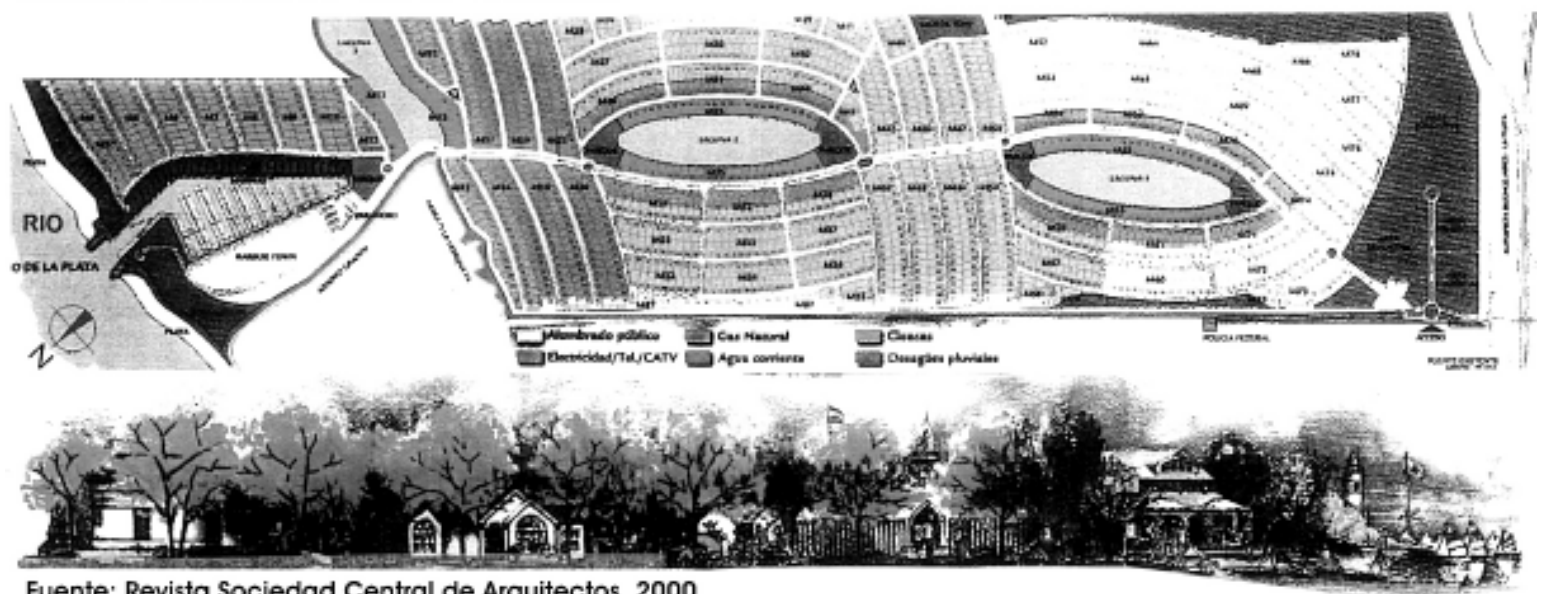

Fuente: Revista Sociedad Central de Arquitectos. 2000 


\section{Juan Carlos Etulain}

Transformaciones Territoriales Recientes en el Litoral Sur de la RMBA Un Camino de Gestión Posible

Figura 6: Adecuaciones normativas.

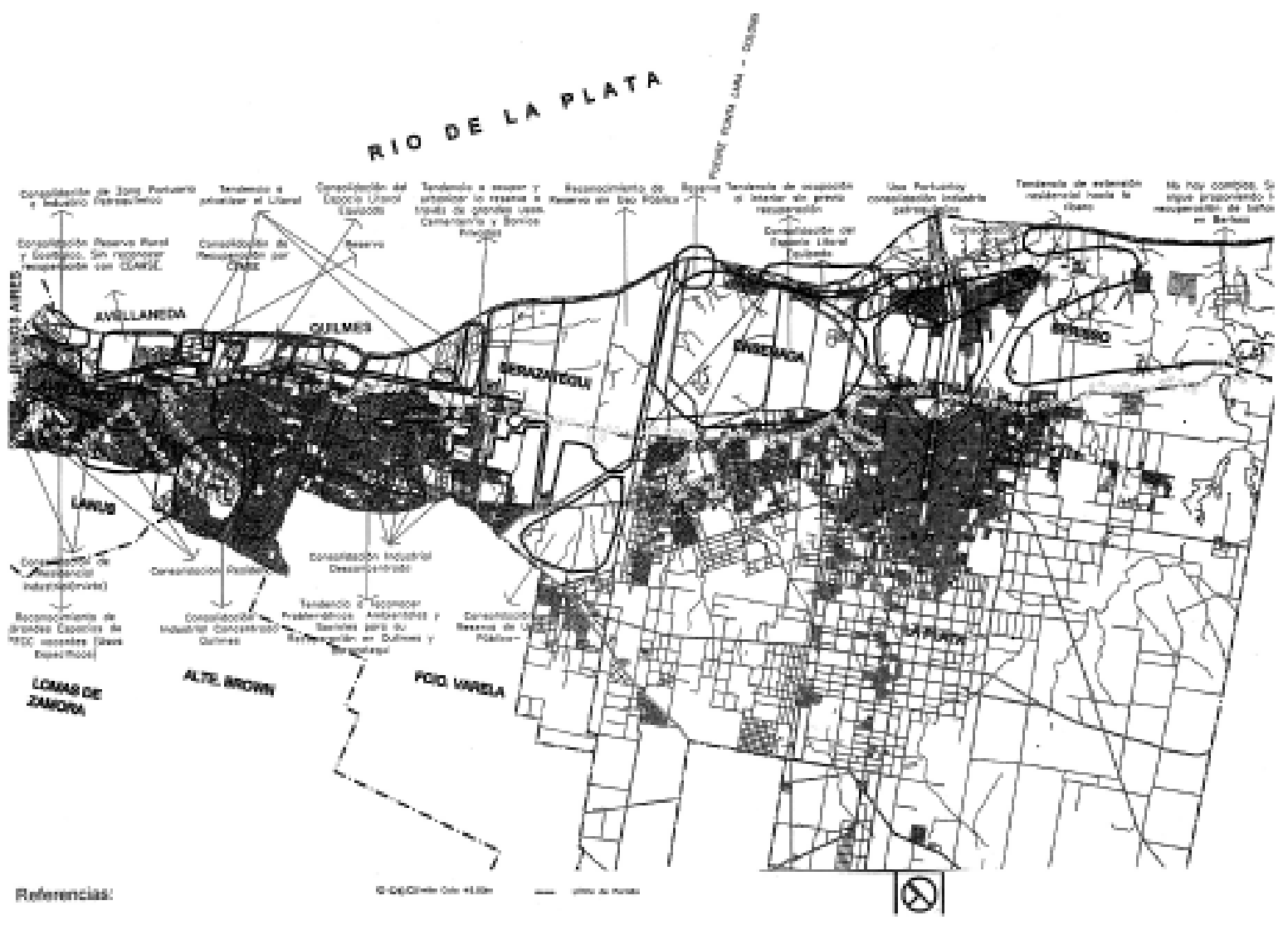

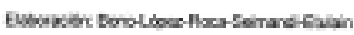




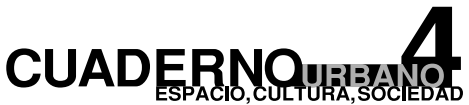

34

Transformaciones Territoriales Recientes en el Litoral Sur de la RMBA Un Camino de Gestión Posible

Figura 7: Transformaciones territoriales

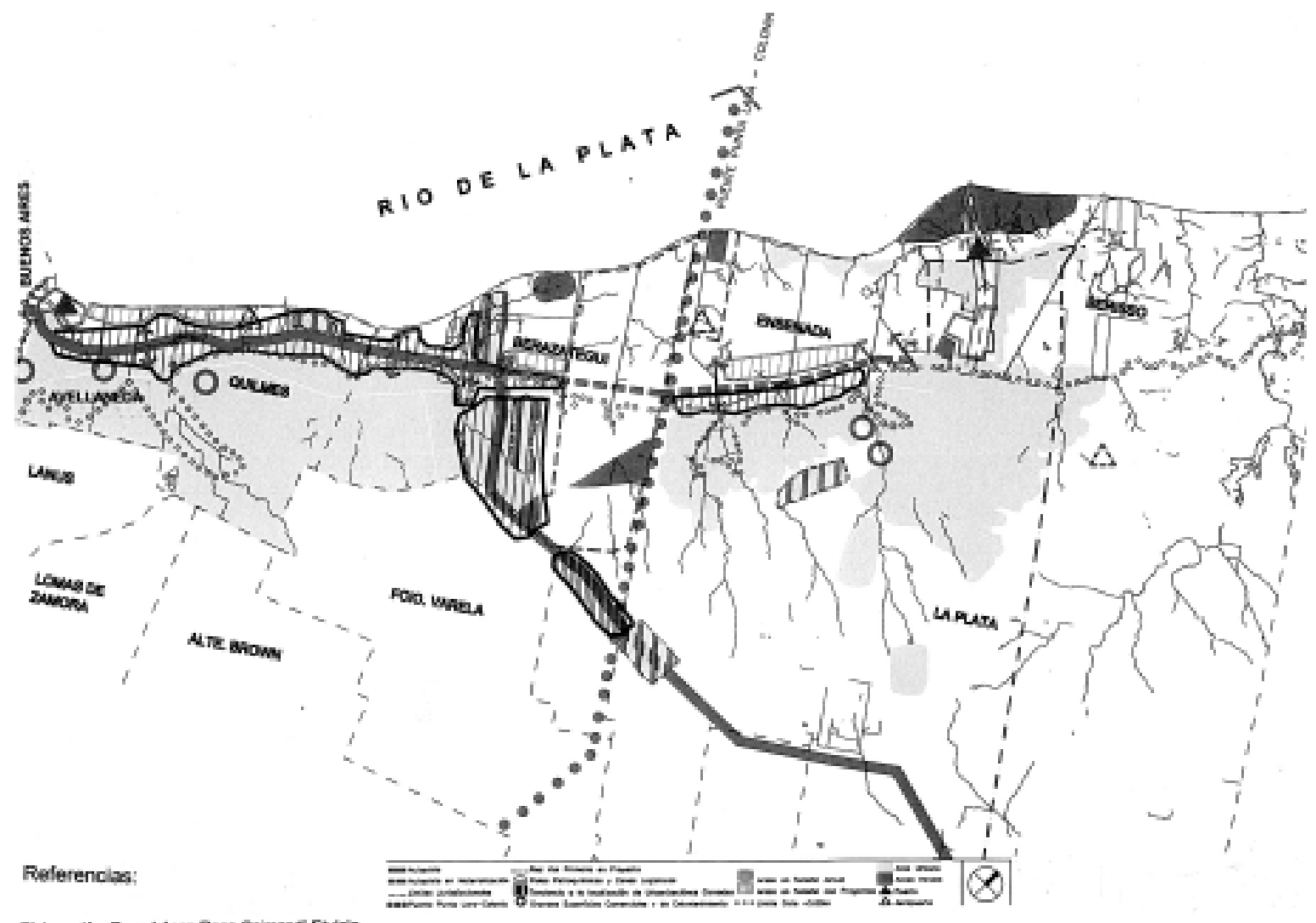

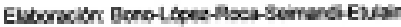




\section{Juan Carlos Etulain}

Transformaciones Territoriales Recientes en el Litoral Sur de la RMBA Un Camino de Gestión Posible

En el marco de las consideraciones efectuadas, las cuales se relacionan especialmente con las expectativas de las inversiones inmobiliarias solamente, cada jurisdicción además ha tomado su territorio valorado internamente, desconociendo la problemática de ocupar el espacio litoral o ser parte de él. Por lo tanto, se ha considerado en forma disímil y a pesar de la homogeneidad que representa la línea litoral y la accesibilidad, se continúa acentuando y posibilitando la fragmentación social y espacial.

Sin embargo, si bien desde la práctica urbanística no se puede impedir la lógica de realización del capital inmobiliario, sí se podría incidir en la formulación de políticas explícitas que enmarquen el uso y la apropiación de este estratégico espacio litoral mediante un tratamiento integrado.

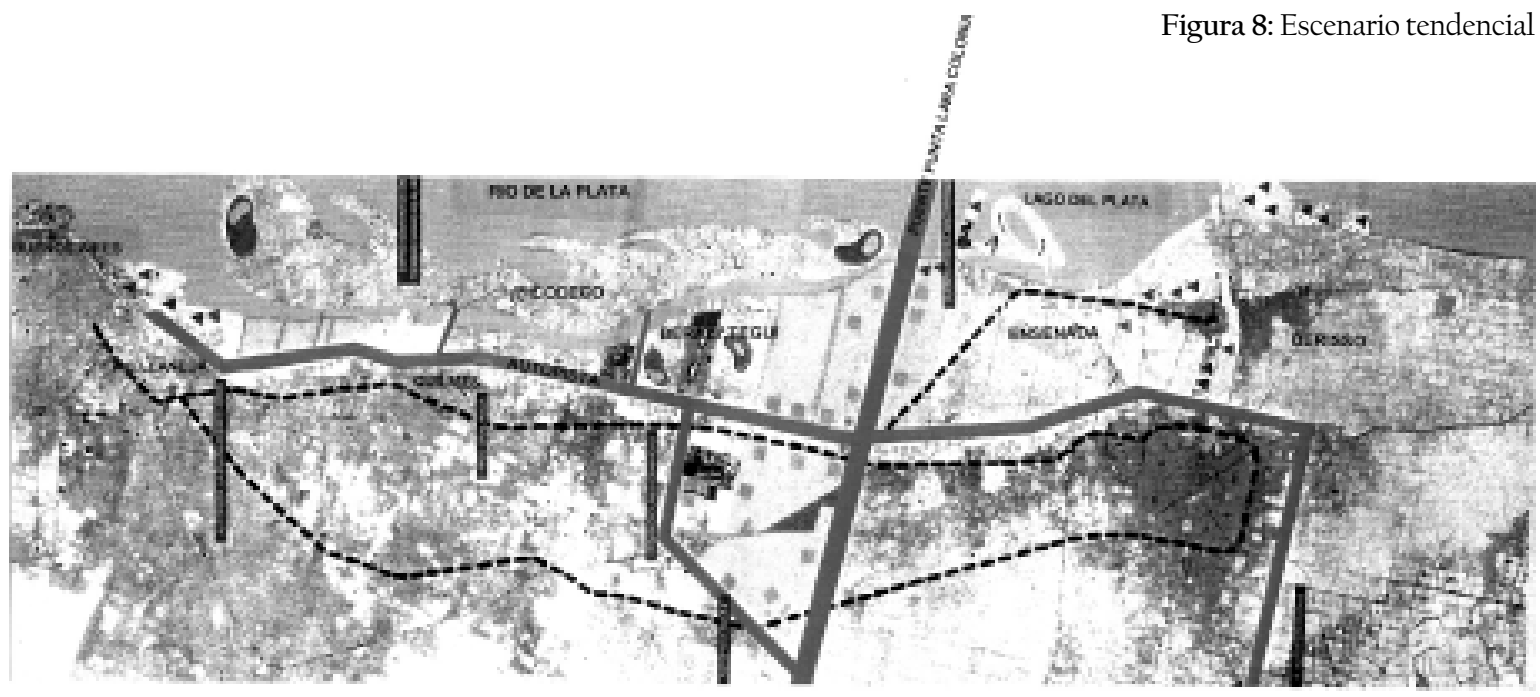

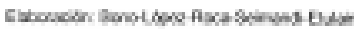




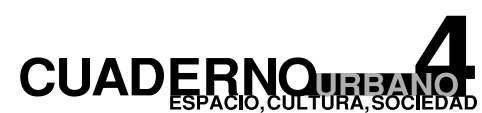

Transformaciones Territoriales Recientes en el Litoral Sur de la RMBA

Un Camino de Gestión Posible

¿Cuáles serían entonces las razones que podrían señalarse para desarrollar un tratamiento integrado del Litoral Sur? Unas son de carácter general, y aparecen vinculadas a la propia singularidad de este espacio, que se relacionan con su pertenencia a una misma región natural, a las distintas jurisdicciones administrativas que lo conforman y a los marcos legales existentes; otras obedecen a las dinámicas social y política propias de la región. En tal sentido, cabría señalar a modo de síntesis, que:

1. La fragilidad del territorio así como su especificidad de litoral no ha sido considerada como parte importante para su protección, rescate y valoración, como espacio público. Sin embargo, en el Código Civil la ribera es espacio público.

2. Es importante cuantitativamente la población que afecta las decisiones, las cuales directa y/o indirectamente se toman sobre la ocupación del territorio litoral.

3. La continua amenaza de inundaciones motivadas por el régimen fluvial del Río de La Plata exige la realización de obras de infraestructura sectoriales que afectan a la conformación física, a la propiedad de la tierra y a los usos del suelo, buscando por un lado mitigar los efectos sobre los asentamientos existentes y por otro, hacer utilizable el valioso suelo aún vacante - circunstacia que merece un plan de ordenamiento y una evaluacion profunda de sus implicancias-.

4. El extraordinario valor ecológico de este frente ribereño, en una región metropolitana tan densamente poblada y degradada desde el punto de vista ambiental.

5. La posibilidad de integración de un circuito ribereño verde, turístico y productivo desde Avellaneda hasta Berisso, que potencie y articule la precaria infraestructura balnearia y recreativa para el uso público existente en Quilmes, Punta Lara y Berisso, e integre el sector productivo de las Quintas de Sarandí, en Avellaneda. 


\section{Juan Carlos Etulain}

Transformaciones Territoriales Recientes en el Litoral Sur de la RMBA

Un Camino de Gestión Posible

\section{ACERCA DE UN CAMINO POSIBLE DE GESTIÓN}

Hasta aquí se han descripto las problemáticas ambientales y de organización territorial históricas y emergentes en los 90, que se pueden sintetizar en una carencia cada vez más acentuada de ordenamiento territorial y ambiental —especialmente en la franja litoral — no sólo porque requeriría un tratamiento especial por sus condiciones de vulnerabilidad, sino porque también debe reconocerse como un espacio complejo, ya sea desde lo jurisdiccional y legal, como desde lo ambiental y social.

Hasta hoy, cada municipio adecuó y/o adaptó sus normas de zonificación de usos al modelo emergente, en forma recortada, parcializada y fragmentaria, caracterizando a cada jurisdicción con una formulación pensada entre medianeras, al igual que los countries, utilizando modelos de asentamiento no apropiados y denotando un vacío para el tratamiento general de la ribera, en lo que se incluye hasta su delimitación.

Sin embargo - y a partir del diagnóstico realizado - se reconoce que la planificación y gestión del espacio litoral debiera surgir a partir del reconocimiento del área como perteneciente a dos tipos de regiones: una urbana metropolitana y la otra natural, por lo tanto, un espacio de gestión compleja y una zona de interfase agua-tierra donde deben intervenir todos los municipios involucrados y la provincia, conformando una región a partir de un ente para dialogar y coordinar un programa apropiado de desarrollo social, de actividades y de cómo utilizar este espacio de características únicas en la geografía mundial.

Como antecedentes de esta asociación se puede mencionar que, desde principios del año 2000 los municipios ribereños del litoral Norte del Río de La Plata han formalizado la conformación de una región común denominada Zona Norte de la RMBA; los municipios de Almirante Brown, Avellaneda, Berazategui y Quilmes formalizaron la región Zona Sur de la RMBA; en tanto que La Matanza, E. Echeverría, Lomas de Zamora y Ezeiza están trabajando para crear la región Zona Centro de la RMBA; y La Plata, Berisso y Ensenada crearon la Región Capital. 


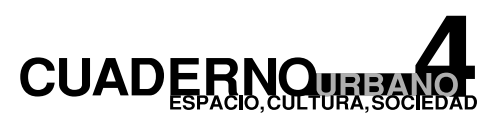

Transformaciones Territoriales Recientes en el Litoral Sur de la RMBA

Un Camino de Gestión Posible

Los objetivos de estas regionalizaciones surgidas de la voluntad política de quienes integran los gobiernos municipales son muy variadas, pero su fundamento más importante es el de encontrar respuestas comunes a problemas de orden social y económico, a la seguridad y el desempleo; también aquellos otros relacionados con la representatividad en la legislatura provincial y encontrar soluciones en conjunto para el desarrollo local, ordenando las actividades de distintos parques tecnológicos e industriales que ya existen en los distritos y que fomentan la cooperación y no la competencia.

Esta política de regionalización, que comienza a practicarse tomando como eje la problemática de la planificación y gestión interjurisdiccional en la provincia de Buenos Aires, tiene como marco principal la Ley Orgánica de las Municipalidades (decreto ley 6769/58) que rige para todos los municipios aunque no permite la autonomía de cada jurisdicción para dictarse su propia Carta Orgánica.

Sin embargo, en el artículo 25 se expresan las competencias, atribuciones y deberes del Departamento Deliberativo - a partir de la sanción de ordenanzas y disposiciones-, reconoce indirectamente los contenidos/temas de las políticas que debieran diseñarse en relación al ordenamiento de un territorio frágil y problemático como el litoral, reafirmado además, por los objetivos y obligaciones que atribuye la ley de suelo 8912 a cada uno de los municipios.

Ahora bien, iqué herramientas o instrumentos permiten la gestión asociativa de los municipios, si se reconoce la necesidad de una política no recortada en lo jurisdiccional? Los municipios, hoy, sólo administran con poderes delegados los asentamientos propios de la ribera como recreos, estacionamientos y otros equipamientos, y el problema de los asentamientos intensivos es tratado como un espacio más hasta que las aguas del río lo desdicen.

Parece ser el consorcio o una sociedad (articulo 4l-inciso d, ley 6769/58 y ley modificatoria 12929/02) la única figura que podría formarse con características intermunicipales, de dos o más municipios, en este caso aquellos que tengan la problemática del río y su cuenca, 


\section{Juan Carlos Etulain}

Transformaciones Territoriales Recientes en el Litoral Sur de la RMBA Un Camino de Gestión Posible

como eje del ordenamiento territorial necesario, a donde pueden y deben sumarse la provincia, la nación (CEAMSE) y el sector privado.

En este sentido y aprovechando como mecanismo institucional para la concertación y coordinación pública, la conformación reciente de las Asociaciones Territoriales de los partidos del Sur de la RMBA y del Gran La Plata, se sugiere proponer al Litoral Sur como Zona de Interés Regional (ZIR).

A partir de este encuadre político, se podrá trabajar en la formulación de Líneas Directrices de Ordenamiento y posibilitar el establecimiento de Programas Coordinados de Actuación (PCA). La elaboración debería estar a cargo de la "Oficina Técnica Interdisciplinaria" integrante del Consorcio o Sociedad, funcionando en relación directa con las máximas autoridades de la Asociación Territorial e interactuando con la sociedad civil. Esta etapa preoperacional (de concepción y elaboración) debería continuarse con otra operativa, luego de su aprobación legal (por cada municipio) para la ejecución de los PCA, a través del mismo ente.

Este mecanismo institucional, está basado en un modo de gestión inspirado en el derecho privado que podría ser financiado, cuando así lo convengan los municipios, con la aplicación de un gravamen destinado al solo y único objeto de financiar la ejecución de obras públicas o servicios. Éstas, definidas por el artículo 59, pueden ser de ornato, salubridad, vivienda, urbanismo, servicios, infraestructura y saneamiento. Otra forma de financiamiento, es el proveniente de la constitución de un fideicomiso de bienes, a partir de la cesión al Consorcio o Sociedad de las tierras públicas que forman parte de la ZIR (ley 12929/02). (Ver Figura 9)

Por lo tanto, a partir de los marcos legales existentes se podría trabajar en esta línea de gestión que, desde la Ley Orgánica permite a los municipios consorciarse o asociarse para prestar servicios o emprender planes y obras de conjunto entre ellos, la provincia, la nación, empresas de servicios e inclusive con los vecinos. En este último caso, el artículo 43, establece que los municipios siempre deben mantener el 51\% de la representación en los órganos 


\section{CUADERNA}

40

Transformaciones Territoriales Recientes en el Litoral Sur de la RMBA
Un Camino de Gestión Posible

directivos y que las utilidades líquidas de los ejercicios serán invertidas en el mejoramiento de la prestación de servicios, aquí para el desarrollo del Litoral Sur. La ley de suelo 8912, además de promocionar los planes integrales e interjurisdiccionales también incorpora la figura de Zonas de Actuación Prioritaria, sustentando legalmente la constitución de la ZIR.

El consorcio o sociedad está pensado para que los organismos públicos coordinen su gestión y programas de intervención, funcionando dentro del derecho privado como una sociedad de economía mixta, necesitando de una Oficina Técnica Interdisciplinaria que coordina acciones que se han decidido y pactado previamente. Tiene autoridades y un presidente, que conformarían el directorio.

Por último y a modo de hipótesis, para consolidar el modelo propuesto se sugieren algunas líneas de trabajo y/o el objeto y funciones que podrían dirigir la gestión del consorcio o sociedad, a saber:

Figura 9: Tierras fiscales en el litoral sur.

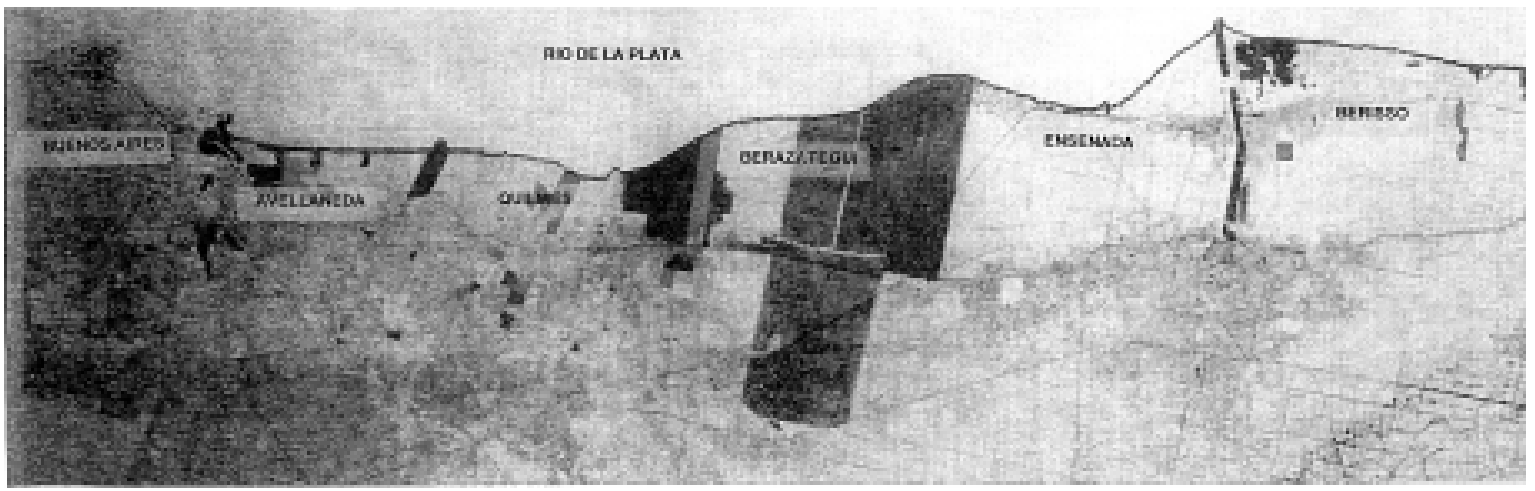

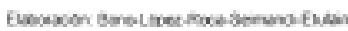




\section{Juan Carlos Etulain}

Transformaciones Territoriales Recientes en el Litoral Sur de la RMBA Un Camino de Gestión Posible

* Manejar una línea de gestión que incorpore a las organizaciones gubernamentales que tengan información/decisión de las grandes infraestructuras que impactan en la región; también debiera incorporarse a las ONG del área y a los organismos privados prestadores de servicios como Aguas Argentinas y Aguas Bonaerenses, con una relación directa en el tratamiento de los vertederos al río.

* Delimitar y definir el espacio que se considerará como franja litoral, con los organismos provinciales con incumbencia, e investigadores universitarios especializados.

* Trazar lineamientos para la gestión de litoral, buscando la compatibilización de las actividades en general, pero teniendo en cuenta una apropiación social equilibrada dentro de cada jurisdicción.

* Elaborar un proyecto de ordenación del Litoral Sur y planificar líneas de desarrollo territorial alternativo.

* Planificar, dirigir y ejecutar por sí o por terceros, los Programas Coordinados de Actuación, a partir de los proyectos y obras que surjan del consenso del Plan.

* Llevar a cabo políticas de educación con respecto a la problemática de los asentamientos inapropiados y en relación a la problemática ambiental del área.

* Administrar la explotación de la ribera otorgando concesiones, locaciones y permisos conforme al régimen legal existente para las áreas ribereñas o que se construyan en su ámbito de actuación. 


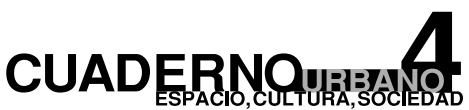

Transformaciones Territoriales Recientes en el Litoral Sur de la RMBA

Un Camino de Gestión Posible

\section{BIBLIOGRAFÍA}

Barragán Muñoz José, 1994; Ordenación, Planificacióny Gestión del Espacio Litoral. Barcelona, España. Editorial OIKOS-

TAU.

Bono Néstor, López Isabel, Roca María Julia, Seimandi Miguel y Etulain Juan Carlos, 2000; “Adecuaciones Normativas del Uso y Ocupación del Suelo en el Marco de las Actuales Transformaciones Territoriales. Caso: Litoral Sur Metropolitano". Ponencia presentada en las $2^{2}$ Jornadas Platenses de Geografía. La Plata, Argentina. Organizadas por el Departamento de Geografía, Facultad de Humanidades y Ciencias de la Educación, UNLP.

Bono Néstor, Laurelli Elsa, López Isabel, Roca María Julia, Seimandi Miguel y Etulain Juan Carlos, 2001; "Escenarios Emergentes en el Litoral Sur Metropolitano". Informe Final Proyecto de Investigación. Programa de Incentivos. La Plata, Argentina. FAU, UNLP.

Cappannini Dino y Mauriño Víctor, 1966; Suelos de la Zona Litoral Estuárica, comprendida entre las Ciudades de Buenos Aires al Norte y La Plata al Sur. 2da Colección Suelo INTA. La Plata, Argentina. INTA.

Etulain Juan Carlos, 1999; "Desarrollo Urbano Territorial. Crecimiento y Forma Urbana en el Escenario de la Reestructuración Global. Estudio de Caso: Litoral Sur de la RMBA". Informe Final, Beca de Formación Superior de la Universidad Nacional de La Plata. La Plata, Argentina.

Ley Orgánica De Las Municipalidades, 1993; Código de faltas municipal y provincial. Texto actualizado. Buenos Aires, Argentina. Editorial Fides.

Leyes provinciales $4614 / 37 ; 6253 / 60 ; 6254 / 60 ; 6769 / 58 ; 8912 / 77$; decreto $11368 / 61$ y ley 12929/02.

Miaczynski Carlos, 1961; Clasificación de las Tierras por Uso. Versión castellana. La Plata, Argentina. INTA.

Normativas Municipales 11451/98, 11541/98 (Avellaneda); 4545/79, 8255/98 (Quilmes); 884/79 y Modificatorias hasta 1994 (Berazategui); 980/83, 3173/98 (Ensenada); 866/85, 2170/98 (Berisso).

Nussbaum, Andrés, 1997; "Sudestadas en el Sur del Gran Buenos Aires. Efectos ambientales sobre el partido de Berazategui". Ponencia presentada en el 6․․ Encuentro de Geógrafos de América Latina. Buenos Aires. Argentina. Instituto de Geografía, Facultad de Filosofía y Letras, UBA. 